SAND80-0365

Unlimited Release UC-25

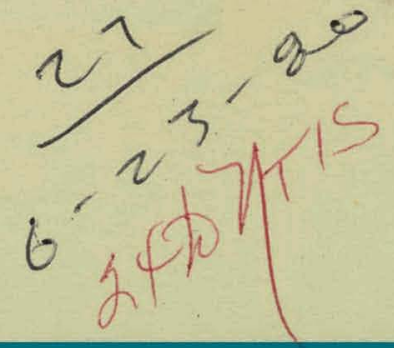

\title{
Toward More Accurate Loss Tangent Measurements in Reentrant Cavities
}

Robert D. Moyer

Prepared by Sandia Laboratories, Albuquerque, New Mexico 87185 and Livermore, California 94550 for the United States Department of Energy under Contract DE-AC04-76DP00789

Printed May 1980 


\section{DISCLAIMER}

This report was prepared as an account of work sponsored by an agency of the United States Government. Neither the United States Government nor any agency Thereof, nor any of their employees, makes any warranty, express or implied, or assumes any legal liability or responsibility for the accuracy, completeness, or usefulness of any information, apparatus, product, or process disclosed, or represents that its use would not infringe privately owned rights. Reference herein to any specific commercial product, process, or service by trade name, trademark, manufacturer, or otherwise does not necessarily constitute or imply its endorsement, recommendation, or favoring by the United States Government or any agency thereof. The views and opinions of authors expressed herein do not necessarily state or reflect those of the United States Government or any agency thereof. 


\section{DISCLAIMER}

Portions of this document may be illegible in electronic image products. Images are produced from the best available original document. 


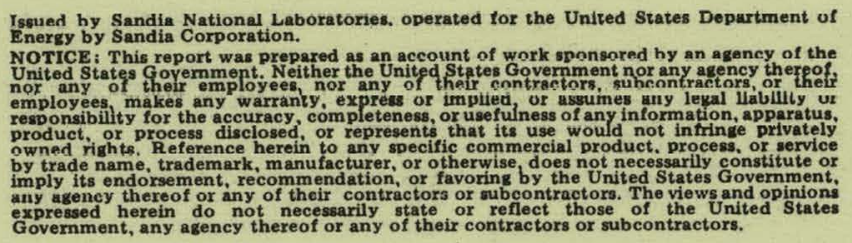

Printed in the United States of America

Available from

National lechnical Intormation Service

U. S. Department of Commerce

5285 Port Royal Road

Springfield, VA 22161

Price: Printed Copy $\$ 4.50$; Microfiche $\$ 3.00$

6.20 
SAND80-0365

Unlimited Release

Printed May 1980
Distribution

Category UC-25

TOWARD MORE ACCURATE LOSS TANGENT MEASUREMENTS IN REENTRANT CAVITIES

Robert D. Moyer

Electrical Standards Division 2552

Sandia National. Laboratories

Albuquerque, NM 87185

\section{ABSTRACT}

Karpova has described an absolute method for measurement of dielectric properties of a solid in a coaxial reentrant cavity. His cavity resonance equation yields very accurate results for dielectric constants. However, he presented only approximate expressions for the 108s tanjent. This report presents more exact expressions for that quantity and summarizes some experimental results.

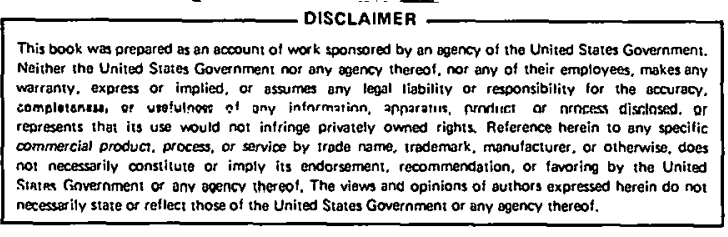


ILLUSTRATIONS

\section{Figure}

1. Cross Section of Reentrant Resonator

2 Reentrant Cavity

$4 \quad z$-Dirscted Current Flowing across an Incremental Band on a Cylindrical surface

TABLE

\section{Table}

1 Results of Dielectric Properties Measurements 
TOWARD MORE ACCURATE LOSS TANGENT

MEASUREMENTS IN REENTRANT CAVITIES

Introduction

Karpova has described an absolute method for measurement of dielectric properties of a solid in a coaxial reentrant cavity. 1 The usefulness of his technique has been recognized by another author ${ }^{2}$ and verified at Sandia Laboratories. Some of the advantages of the technique are.

- The solution is "exact" so that a wide range of dielectric constants may be accommodated.

- No standards are required to calibrate the cavity.

- The technique is convenient for very-high-frequency (VHF) and ultra-highfrequency (UHF) measurements because the largest dimension of the cavity is of the order of a quarter wavelength.

- The required sample shape. is a simple right circular cylinder whose diameter-to-length ratio is not critical. For example, a $1: 1$ ratio is very convenient when preparing sample specimens from brittle materials.

The resonance equation given by Karpoval yields quite accurate results for the dielectric constant; however, he presented only approximate expressions for ioss tangent. The purpose of this report is to give more exact expressions. A drawback of this measurement technique is the extensive computation required, but, for those with access to a computer, this drawback becomes rather insignificant.

Summary of Previous Results and Formulation of the Problem

For the sake of completeness, the resonance equation derived by Karpova is repeated in Eq. (1); and its symbolism is defined. With few exceptions, the notation of Karpova is retained in this paper, the main exception being that all work here is in the mks system of units.

The resonance equation is

$$
\frac{\pi^{2}}{2} R_{0}^{A}+\sum_{n=1}^{\infty} \frac{R_{n}^{A} \sin ^{2}(\pi a n)}{a^{2} n^{2}}=\frac{\pi^{2}}{2 a} R_{0}^{B}+s u M \text {, }
$$


where

$$
\operatorname{SUM}=\sum_{m=1}^{\infty}\left\{\frac{\left(\sum_{n=1}^{\infty} R_{n}^{A} \frac{\sin ^{2}(\pi a n)}{a^{2} n^{2}-m^{2}}\right)^{2}}{\sum_{n=1}^{\infty} \frac{R_{n}^{A} a^{2} n^{2} \sin ^{2}(\pi a n)}{\left(a^{2} n^{2}-m^{2}\right)^{2}}-\frac{\pi^{2}}{4 a} R_{m}^{B}}\right\}
$$

In these equations, $a$ is the ratio of sample length a to cavity length $L$, as shown in Figure l, which is a cross section of the reentrant cavity.

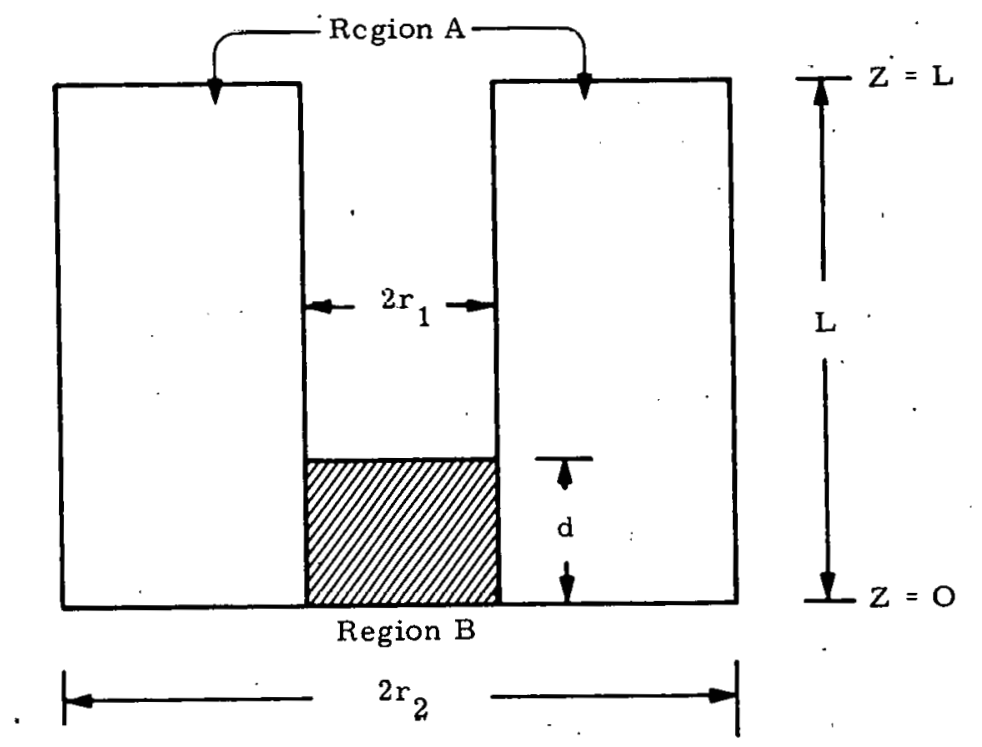

Figurc 1. Cross Section of Reentrant Resonator

$$
a=\frac{d}{L}
$$

As suggested by Figure 1, the unknown material occupies region $B$ while region $A$ is filled with air.

$$
\begin{aligned}
& R_{0}^{A}=j \cdot \frac{r_{1}\left(k_{0} r_{1}\right)}{G_{0}\left(k_{0} r_{1}\right)} \\
& R_{n}^{A}=j \frac{k_{0}}{k_{n}{ }^{A}} \frac{D_{1 n}\left(k_{n}{ }^{A} r_{1}\right)}{D_{0 n}\left(k_{n}{ }^{A} r_{1}\right)} \\
& R_{0}^{B}=j \sqrt{\varepsilon_{x r}} \frac{J_{1}\left(k r_{1}\right)}{J_{0}\left(k r_{1}\right)} \\
& R_{m}^{B}=j \frac{k}{k_{m}^{B}} \sqrt{\varepsilon_{x r}} \frac{I_{1}\left(k_{m}{ }^{B} r_{1}\right)}{I_{0}\left(k_{m}{ }^{B} r_{1}\right)}
\end{aligned}
$$


In Eqs. (4) through (7)

$$
\begin{aligned}
& j=\sqrt{-1}, \\
& G_{0}\left(k_{0} r\right)=J_{0}\left(k_{0} r\right) N_{0}\left(k_{0} r_{2}\right)-J_{0}\left(k_{0} r_{2}\right) N_{0}\left(k_{0} r\right), \\
& G_{1}\left(k_{0} r\right)=J_{1}\left(k_{0} r\right) N_{0}\left(k_{0} r_{2}\right)-J_{0}\left(k_{0} r_{2}\right) N_{1}\left(k_{0} r\right),
\end{aligned}
$$

where

$$
\begin{aligned}
\mathrm{k}_{0} & =\omega \sqrt{\mu_{0} \varepsilon_{0}} \\
\omega & =\text { radian resonant frequency, } \\
\mu_{0} & =4 \pi \times 10^{-7} \mathrm{H} / \mathrm{m}, \\
\varepsilon_{0} & =8.8542 \times 10^{-12} \mathrm{~F} / \mathrm{m},
\end{aligned}
$$$$
\mathrm{J}_{i} \text { and } \mathrm{N}_{i} \text { are Bessel functions of the first }
$$$$
\text { and second kind, respectively, of order } i \text {, }
$$$$
r_{1} \text { and } r_{2} \text { are radii defined in Figure } 1 \text {, }
$$

$$
\begin{aligned}
& \left(k_{n}^{A}\right)^{2}=-\left(k_{c n}^{A}\right)^{2}=\left(\frac{n \pi}{L}\right)^{2}-k_{0}^{2}, \\
& D_{O n}\left(k_{n}{ }^{A} r\right)=I_{0}\left(k_{n}{ }^{A} r\right) K_{0}\left(k_{n}{ }^{A} r_{2}\right)-I_{0}\left(k_{n}{ }^{A} r_{2}\right) K_{0}\left(k_{n}{ }^{A} r\right) . \\
& D_{1 n}\left(\kappa_{n}{ }^{A} r\right)=I_{1}\left(k_{n}{ }^{A} r\right) K_{0}\left(k_{n}{ }^{A} r_{2}\right)+I_{0}\left(k_{n}{ }^{A} r_{2}\right) K_{1}\left(k_{n}{ }^{A} r\right), \\
& I_{i} \text { and } K_{i} \text { are modified Bessel functions of the first } \\
& \text { and second kind, respectively, of order } i \text {, } \\
& \varepsilon_{x r} \text { is the relative dielectric constant of the material } \\
& \text { in Region } B \text {, } \\
& k=\sqrt{E x r}_{0} \text {, and } \\
& \left(k_{m}^{B}\right)^{2}=-\left(k_{c m}^{B}\right)^{2}=\left(\frac{\pi m}{a L}\right)^{2}-\varepsilon_{x r_{0}}{ }^{2} .
\end{aligned}
$$

Note that the factor $j=\sqrt{-1}$ cancels out of Eq. (1) so that it is a purely real equation. The wave numbers $\mathrm{k}_{\mathrm{cn}}{ }^{\mathrm{A}}$ and $\mathrm{k}_{\mathrm{cm}}{ }^{\mathrm{B}}$ appear only in Eqs. (12) and (16). However, they are quite frequently encountered in other literature, ${ }^{3}$ so their relationships to the quantities $k_{n}{ }^{A}$ and $k_{m}{ }^{B}$, which are used extensively in the present report, are given. This completes the definition of all notation in resonance Eq. (1). 
In the sections which follow, expressions for the fields in the two regions are needed. These are reproduced in Eqs. (17) through (22).

In region $A$,

$$
\begin{aligned}
& E_{z}^{A}=a_{0} \frac{G_{0}\left(k_{0} r\right)}{G_{0}\left(k_{0} r_{1}\right)}+\sum_{n=1}^{\infty} c_{n} \frac{D_{0 n}\left(k_{n}{ }^{A} r\right)}{D_{0 n}\left(k_{n}{ }^{A} r_{1}\right)} \cos \left(\frac{\pi n z}{L}\right) \\
& E_{r}^{A}=\frac{\pi}{L} \sum_{n=1}^{\infty} \frac{n c_{n}}{k_{n}{ }^{A}} \frac{D_{1 n}\left(k_{n}{ }^{A} r\right)}{D_{O n}\left(k_{n}{ }^{A} r_{1}\right)} \sin \left(\frac{\pi n}{L} z\right)
\end{aligned}
$$

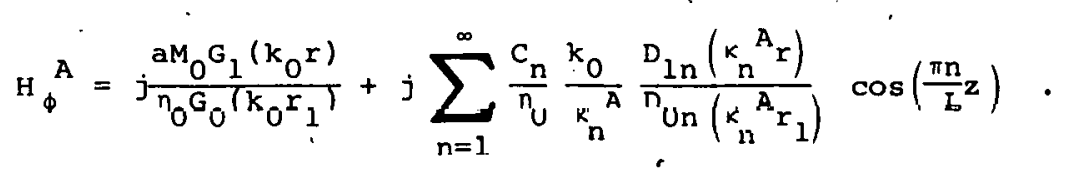

In region $B$,

$$
\begin{aligned}
& F_{z}^{B}=M_{0} \frac{J_{0}(k r)}{J_{0}\left(k r_{1}\right)}+\sum_{m=1}^{\infty} M_{m} \frac{I_{0}\left(k_{m}{ }^{B} r\right)}{I_{0}\left(k_{m}{ }^{B} r_{1}\right)} \cos \left(\frac{\pi m}{a L} z\right), \\
& E_{r}^{B}=\sum_{m=1}^{\infty} \frac{\pi m}{a L k_{m}{ }^{B}} M_{m} \frac{I_{1}\left(k_{m}{ }^{B} r\right)}{I_{0}\left(k_{m}{ }^{B} r_{1}\right)} \sin \left(\frac{\pi m}{a L} z\right), \\
& \left.H_{\phi}^{B}=\right\rfloor \frac{\sqrt{\varepsilon} \times r_{0}}{n_{0}} M_{0} \frac{J_{1}(k r)}{J_{0}\left(k r_{1}\right)}+ \\
& +j \frac{\sqrt{\ddot{\varepsilon}_{x r}}}{n_{0}} \sum_{m=1}^{\infty} \frac{k}{{ }^{B}{ }^{B}} M_{m} \frac{I_{l}\left(k_{m}{ }^{B} r\right)}{I_{0}\left(k_{m}{ }^{B}{ }{ }_{1}\right)} \cos \left(\frac{\pi m z}{a L}\right),
\end{aligned}
$$

where

$$
c_{n}=2 M_{0}\left[\frac{\sin (\pi a n)}{\pi n}+\frac{I}{\pi} \sum_{m=1}^{\infty}(-1)^{m} \frac{M_{m}}{M_{n}} n \frac{0 i n(\pi a n)}{\left(n^{2}-\frac{m^{2}}{a^{2}}\right)}\right]
$$

and

$$
\begin{aligned}
& "_{0}=376.73 \text { ohms = characteristic impedance of free space. } \\
& M_{0} \text { will turn out to be arbitrary and }
\end{aligned}
$$




$$
\frac{M_{m}}{M_{0}}=\frac{(-1)^{m} \sum_{n=1}^{\infty} R_{n}^{A} \frac{\sin ^{2}(\pi a n)}{a^{2} n^{2}-m^{2}}}{m^{2}\left[\frac{\pi^{2} R_{m}^{B}}{4 a}-\sum_{n=1}^{\infty} \frac{R_{n}{ }^{A} a^{2} n^{2} \sin ^{2}(\pi a n)}{\left(a^{2} n^{2}-m^{2}\right)^{2}}\right]} .
$$

Finally, the loss tangent. (TAND) of the sample is given by

$$
\text { TAND }=\left(\frac{W_{A}+W_{B}}{W_{B} Q}\right)-\left(\frac{P_{W}+P_{C}+P_{J}}{w W_{B}}\right) \text {. }
$$

where

$$
\begin{aligned}
\mathrm{W}_{\mathrm{A}}= & \text { maximum energy stored in } A \text { region of resonator } \\
\mathrm{W}_{\mathrm{B}}= & \text { maximum energy stored in } \mathrm{B} \text { region of resonator } \\
Q= & \text { measured, loaded } Q \text { of the resonator with sample } \\
& \text { in place } \\
P_{\mathrm{W}}= & \text { power dissipated in the conducting resonator } \\
& \text { walls } \\
P_{C}= & \text { power dissipated in the external source and } \\
& \text { receiver circuits, and } \\
P_{J}= & \text { power dissipated in the joint between the center } \\
& \text { conductor and base plate of the resonator. }
\end{aligned}
$$

The $\mathrm{P}_{\mathrm{J}}$ term did not appear in Karpova's analysis. It is added here because of the manner in which our resonators, were constructed.

To (a) relax the required tolerances on dimension d (see Figure 1 ) of the sample, and (b) permit samples of different lengths to be measured, the center conductor post of the cavity can slide in the z direction (see F1gure 2 ). Once the sample is in place and the cover is attached (at the $z=0$ plane), a screw is used to force intimate contact between the center conductor, the sample, and the cover of the cavity. This is done to minimize the air gap errors which are particularly troublesome when measuring samples with a large dielectric constant. Unfortunately, small losses occur in the sliding joint; these are accounted for by the $P_{J}$ term. $P_{C}$ is also computed differently from Karpova; this is described under "Expressions for Power Losses in the Resonator," later in this report. 

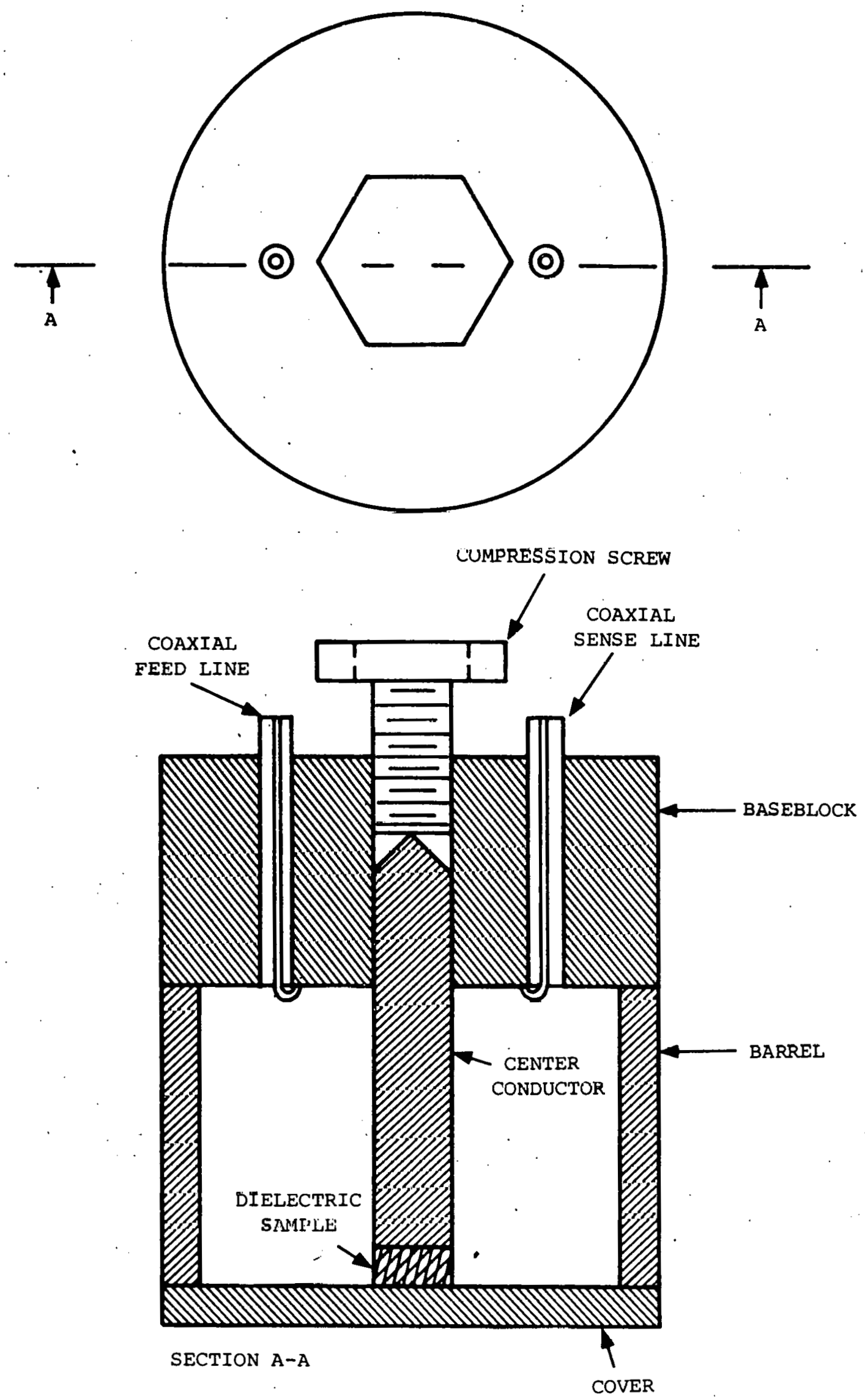

Figure 2. Reentrant Cavity 
All necessary information is now at hand to proceed with the "exact" computations of the terms $W_{A^{\prime}} W_{B^{\prime}} P_{W^{\prime}} P_{C^{\prime}}$ and $P_{J}$ on the right side of Eq. (25). "Exact" is enclosed in quotation marks because the fields given by Eqs. (17) through (22) were derived under the assumption that the cavity. walls were lossless. Nevertheless, they will be used to calculate the effects of losses which do occur in the walls.

Expressions for Stored Energies in the Resonator

Total Energy Stored in Region A

The total energy stored in region $A, W_{A}$ is given by

$$
\mathrm{w}_{\mathrm{A}}=\mathrm{W}_{\mathrm{Az}}+\mathrm{w}_{\mathrm{Ar}} \text {, }
$$

where $W_{A z}$ and $w_{A r}$ are the energies stored in the $z$ and $r$ (radial) $E$ fields, respectively. The term $\mathrm{W}_{\mathrm{Az}}$ is computed first.

$$
\begin{aligned}
& \text { Computation of } \mathrm{W}_{\mathrm{Az}} \\
& W_{A z}=\frac{\varepsilon_{0}}{2} \int_{r}^{r}\left[\int_{0}^{L}\left|E_{z}^{A}\right|^{2} d z\right] 2 \pi r d r
\end{aligned}
$$

By using Eq. (17), Eq. (27) may be rewritten as

$$
\begin{aligned}
w_{A z} & =\pi \varepsilon_{0} \int_{r_{1}}^{r_{2}} \int_{0}^{L}\left[a M_{0} \frac{G_{0}\left(k_{0} r\right)}{G_{0}\left(k_{0} r_{1}\right)}+c_{1} \frac{D_{01}\left(\kappa_{1}^{A} r\right)}{D_{01}\left(k_{1}^{A} r_{1}\right)} \cos \left(\frac{\pi z}{L}\right)+\right. \\
& +\ldots]\left[a_{0} \frac{G_{0}\left(k_{0} r\right)}{G_{0}\left(k_{0} r_{1}\right)}+c_{1} \frac{D_{01}\left(\kappa_{1}^{A} r\right)}{D_{01}\left(\kappa_{1}^{A} r_{1}\right)} \cos \left(\frac{\pi z}{L}\right)+\ldots\right] d z d r
\end{aligned}
$$

Considering first the integration over $z$, it is seen that each term will be of the form

$$
\int_{0}^{L} \cos \left(\frac{\pi i z}{L}\right) \cos \left(\frac{\pi j z}{L}\right) d z \text {, }
$$

where $i$ and $j$ have, independently, any integer value between 0 and $\infty$ If $i \neq j$, it is easily shown that the integral vanishes. If $i=j \neq 0$,

$$
\int_{0}^{L} \cos \left(\frac{\pi i z}{L}\right) \cos \left(\frac{\pi i z}{L}\right) d z=\frac{L}{2} .
$$

If $i=j=0$, . 


$$
\int_{0}^{L} 1 \cdot 1 d z=L
$$

From these orthogonality results, Eq. (28) may be rewritten as

$$
W_{A 2}=\pi \varepsilon_{0} \int_{r_{1}}^{r_{2}} r\left\{a^{2} L M_{0}{ }^{2} \frac{G_{0}{ }^{2}\left(k_{0} r\right)}{G_{0}{ }^{2}\left(k_{0} r_{1}\right)}+\frac{L}{2} \sum_{n=1}^{\infty}\left[C_{n} \frac{D_{0 n}\left(k_{n}{ }_{n} r\right)}{D_{0 n}\left(k_{n}^{A} r_{1}\right)}\right]^{2}\right\} d x
$$

Now, rewritc Eq. (31) as

$$
\mathrm{W}_{\mathrm{Az}}=\mathrm{I}_{\mathrm{AOz}}+\sum_{\mathrm{n}=1}^{\infty} \mathrm{I}_{\mathrm{Anz}} \text {. }
$$

Comparing Eqs. (31) and (32) and incorporating Eq. (9) gives

$$
\begin{aligned}
& I_{A 0 Z}=\frac{\pi \varepsilon_{U^{a}}{ }^{2} L M_{0}{ }^{2}}{G_{0}{ }^{2}\left(k_{0} r_{1}\right)}\left[N_{0}{ }^{2}\left(k_{0} r_{2}\right) \int_{r_{1}}^{r^{2}} J_{0}^{2}\left(k_{0} r\right) r d r-\right. \\
& -2 N_{0}\left(k_{0} r_{2}\right) J_{0}\left(k_{0} r_{2}\right) r_{1}^{r} J_{0}^{2}\left(k_{0} r\right) N_{0}\left(k_{0} r\right) r d r+ \\
& \left.+J_{0}^{2}\left(k_{0} r_{2}\right) r_{1}^{r} \int^{2} N_{0}^{2}\left(k_{0} r\right) r d r\right] \text {. }
\end{aligned}
$$

Eq. (33) is now rewritten, using the notation which will be employed throughout the romaindor of thio report:

$$
\begin{aligned}
I_{A 0 z} & =\frac{\pi \varepsilon_{0} a^{2} L M_{0}{ }^{2}}{G_{0}{ }^{2}\left(k_{0} r_{1}\right)}\left[N_{0}{ }^{2}\left(k_{0} r_{2}\right) \operatorname{QJJR}\left(r_{1}, r_{2}, 0, k_{0}, k_{0}\right)-\right. \\
& -2 N_{0}\left(k_{0} L_{2}\right) J_{0}\left(k_{0} r_{2}\right) \operatorname{UNN}\left(r_{1}, r_{2}, u, k_{0}, k_{0}\right)+ \\
& \left.+J_{0}{ }^{2}\left(k_{0} r_{2}\right) \operatorname{ONNR}\left(r_{1}, r_{2}, 0, k_{0}, k_{0}\right)\right] .
\end{aligned}
$$

The rationale for this notation. is as follows: Throughout this report, integrals such as those appearing in Eq. (33) appear repeatedly. Each integral can be expressed in closed form so function subroutines were written to evaluate them in the FORTRAN program KARPOVA, which implements this technique. The form of the calls to three of those function subroutines appears in Eq. (34). For example, the significance of the call $\operatorname{QJNR}\left(r_{1}, r_{2}, 0, k_{0}, k_{0}\right)$ is as follows: The last three letters of the function name indicate that the integrand is the product of a $J$ Bessel function, an $\mathrm{N}$ Bessel function, and the independent variable $r$. The first two arguments of the function specify the range of the integration to be $r_{1} \leq r \leq r_{2}$. The third argument specifies the order of both Bessel functions to be 0 . The fourth function argument specifies that the argument of the first Bessel function is $k_{0} r$. The fifth 
function argument indicates that the argument of the second Bessel function is also (in this case) $k_{0} r$. Since one of the purposes of this report is to provide documentation for the KARPOVA program, the functional notation is used in this report. Explicit expressions for each definite integral appear in Appendix $A$.

If one compares Eqs. (31) and (32) and incorporates Eq. (13), Eq. (35) results.

$$
\begin{aligned}
& I_{A n z}=\frac{\pi \varepsilon_{0} L C_{n}{ }^{2}}{2 D_{0 n}{ }^{2}\left(\kappa_{n}{ }^{A} r_{1}\right)}\left[K_{0}{ }^{2}\left(\kappa_{n}{ }^{A} r_{2}\right) \operatorname{QIIR}\left(r_{1}, r_{2}, 0, \kappa_{n}{ }^{A}, k_{n}{ }^{A}\right)-\right. \\
& -2 K_{0}\left(k_{n}{ }^{A} r_{2}\right) I_{0}\left(k_{n}{ }^{A} r_{2}\right) \operatorname{oKIR}\left(r_{1}, r_{2}, 0, k_{n}^{A}, k_{n}{ }^{A}\right)+ \\
& \left.+I_{0}^{2}\left(\kappa_{n}^{A} r_{2}\right) \operatorname{QKKR}\left(r_{1}, r_{2}, 0, \kappa_{n}^{A}, k_{n}^{A}\right)\right] \text {. }
\end{aligned}
$$

Eqs. (32), (34) and (35) may now be combined to determine $\mathrm{w}_{\mathrm{Az}}$.

$$
\begin{aligned}
& \text { Computation of } \mathrm{w}_{\mathrm{Ar}} \\
& \mathrm{w}_{\mathrm{Ar}}=\frac{\varepsilon_{0}}{2} \int_{r_{1}}^{\mathrm{r}}\left[\int_{0}^{\mathrm{L}}\left|\mathrm{E}_{\mathrm{r}}^{\mathrm{A}}\right|^{2} \cdot \mathrm{dz}\right] 2 \pi \mathrm{rdr}
\end{aligned}
$$

BY applying Eq. (18) and the orthogonality properties already discussed, Eq. (36) becomes

$$
w_{A r}=\frac{\varepsilon_{0} \pi^{3}}{2 I} \sum_{n=1}^{\infty}\left[\frac{n_{n}}{k_{n}{ }^{A} D_{O n}\left(k_{n}{ }^{A} r_{1}\right)}\right]^{2} \int_{r_{1}}^{r} D_{1 n}{ }^{2}\left(k_{n}{ }^{A}\right) r d r .
$$

Finally, by using F.q. (14) and the integral notation, the expression for $W_{A r}$ becomes

$$
\begin{aligned}
& \dot{w}_{A r}=\frac{\varepsilon_{0}{ }^{3}}{2 L} \sum_{n=1}^{\infty}\left\{\left[\frac{n C_{n}}{\dot{k}_{n}{ }^{{ }^{A} D_{O n}}{ }{ }_{n}{ }^{A}{ }_{r_{1}}}\right]^{2}\right. \text {. } \\
& {\left[\mathrm{k}_{0}{ }^{2}\left(\mathrm{k}_{n}{ }^{A} r_{2}\right) \operatorname{QIIR}\left(r_{1}, r_{2}, 1, k_{n}^{A}, k_{n}^{A}\right)+\right.} \\
& +2 K_{0}\left(k_{n}{ }^{A} r_{2}\right) I_{0}\left(k_{n}{ }^{A} r_{2}\right) \operatorname{QKIR}\left(r_{1}, r_{2}, 1, k_{n}^{A}, k_{n}^{A}\right)+ \\
& \left.\left.+I_{0}^{2}\left(k_{n}{ }^{A} r_{2}\right) \operatorname{QKKRR}\left(r_{1}, r_{2}, 1, k_{n}{ }^{A}, k_{n}{ }^{A}\right)\right]\right\} \text {. }
\end{aligned}
$$

$W_{A}$ is now determined by Eqs. $(26),(32),(34),(35)$, and $(38)$.

Total Energy Stored in Region B

The total energy stored in region $B, W_{B}$, is given by 


$$
\mathrm{w}_{\mathrm{B}}=\mathrm{w}_{\mathrm{Bz}}+\mathrm{w}_{\mathrm{Br}}
$$

where $W_{B z}$ and $W_{B r}$ are the energies stored in the $z$ and $r$ directed $E$. fields, respectively.

$$
\begin{aligned}
& \text { Computation of } \mathrm{W}_{\mathrm{Bz}} \\
& w_{B z}=\frac{\varepsilon_{0} \varepsilon_{x x}}{2} \int_{0}^{r}\left[\int_{0}^{d}\left|E_{z}^{B}\right|^{2} d z\right] 2 \pi r d r
\end{aligned}
$$

By using Eq. (20) and the orthogonality relations and recalling that $d=a L$, one obtains

$$
\begin{aligned}
& W_{B z}=\frac{\varepsilon_{0}{ }_{B} \mathrm{xr}_{0}{ }^{2} \pi d}{J_{n}{ }^{2}\left(k r_{1}\right)} \operatorname{QJJR}\left(0, r_{l}, 0, k, k\right)+
\end{aligned}
$$

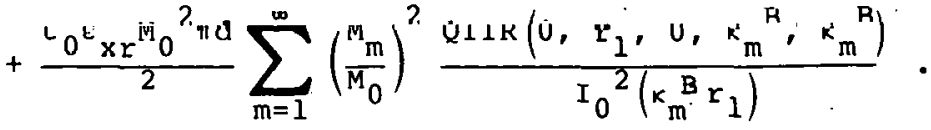

$$
\frac{\text { Computation of } \mathrm{W}_{\mathrm{Br}}}{\mathrm{W}_{\mathrm{Br}}=\frac{{ }^{\varepsilon_{0}} \varepsilon_{\mathrm{E}}}{2} \int_{0}^{r}\left[\int_{0}^{\mathrm{d}}\left|E_{r}{ }^{\mathrm{B}}\right|^{2} \mathrm{dz}\right] 2 \pi r \mathrm{dr} r}
$$

Employing Eq. (2l) and the orthogonality relations yields

$$
\begin{gathered}
W_{B r}=M_{0}{ }^{2} \varepsilon_{0} \varepsilon_{x I} \pi^{d} \sum_{m=1}^{\infty}\left(\frac{\pi m}{a L \kappa_{m}{ }^{D}}\right)^{2}\left(\frac{M_{m}}{M_{0}}\right)^{2} . \\
\cdot \frac{\operatorname{QIIR}\left(0, r_{1}, 1, \kappa_{m}^{B}, \kappa_{m}^{B}\right)}{I_{0}{ }^{2}\left(\kappa_{m}{ }^{B} r_{l}\right)} .
\end{gathered}
$$

Equations (39), (4l), and (43) are combined to yield $W_{B}$.

Expressions for Power Losses in the Resonator

\section{Power Losses in the Walls of the Resonator}

The total power dissipated in the resonator walls. $P_{W}$, is broken out into six components, i.e.,

$$
P_{W}=P_{C B}+P_{C A}+P_{O C}+P_{b}+P_{i c}+P_{e} \text {, }
$$

where

$$
\begin{aligned}
& { }^{P_{C B}} \text { is the power dissipated in region } B \text { of the } \\
& \text { cover (at } z=0)
\end{aligned}
$$


$C A$ is the power dissipated in region $A$ of the cover

$P_{\text {oc }}$ is the power dissipated in the outer conductor of the resonator at $r=r_{2}$

$P_{b}$ is the power dissipated in the base plate at $z=L$

$P_{i c}$ is the power dissipated on the periphery of the inner conductor at $r=r_{1}$

$\mathrm{P}_{\mathrm{e}}$ is the power dissipated on the end of the center conductor at $z=d$.

Computation of $\mathrm{P}_{\mathrm{CB}^{--}}$By referring to figure 3, it is readily seen that the power $\mathrm{dP}_{\mathrm{CB}}$ dissipated in an incremental annular area on the cover plate is given by

$$
d P_{c B}=\frac{\left|I_{r m s}\right|^{2} R_{s c} d r}{2 \pi r} .
$$

In Eq. (45), Irms is the total rms current which flows radially across the annular region bounded by $r$ and $r+d r$. (Note: Since the only H fields present are $\phi$-directed, the only currents which can flow in the cover are radially directed.)

$R_{s c}$ is the surface resistivity of the cover and is given by ${ }^{3}$

$$
R_{S C}=\sqrt{\pi F_{\mu_{1}} \rho_{1}}
$$

where $\mathrm{f}$ is the loaded cavity resonant frequency in $\mathrm{Hz}, \mu_{l}$ is the permeability of the cover material, and $\rho_{1}$ is its bulk resistivity.

$I_{r m s}$ is related to the $H$ field as

$$
\left|I_{r m s}\right|=2 \pi r \frac{\left|\mathrm{H}_{\phi} \mathrm{B}\right|}{\sqrt{2}}
$$

so that Eq. (45) becomes

$$
\mathrm{dP}_{\mathrm{CB}}=\pi \mathrm{R}_{\mathrm{SC}}\left|\mathrm{H}_{\phi}{ }^{\mathrm{B}}\right|^{2} \mathrm{rdr} .
$$




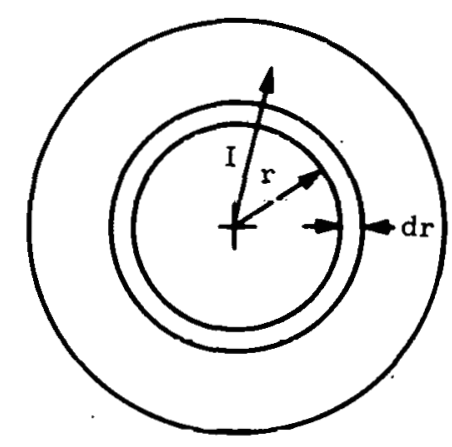

Figure 3. Incremental Annular Area

From Eq. (22),

$$
\begin{aligned}
& \left|\mathrm{H}_{\phi}^{B}\right|^{2}=\frac{\mathrm{C}_{\mathrm{xr}}}{\mathrm{n}_{0}{ }^{2}} \mathrm{M}_{0}^{2}\left[\frac{\mathrm{J}_{1}{ }^{2}(\mathrm{kr})}{\mathrm{J}_{0}{ }^{2}\left(\mathrm{kr}_{1}\right)}+\right. \\
& +2 \frac{k}{J_{0}\left(k r_{1}\right)} \sum_{m=1}^{\infty}\left(\frac{M_{m}}{M_{0}}\right) \frac{J_{1}(k r) I_{1}\left(k_{m}^{B} r\right) S_{1}}{I_{0}\left(k_{m}^{B} r_{1}\right) k_{m}^{B}}+ \\
& \left.+k^{2} \sum_{i=1}^{\infty} \sum_{j=1}^{\infty}\left(\frac{M_{i}}{M_{0}}\right)\left(\frac{M_{j}}{M_{0}}\right) \frac{I_{1}\left(k_{i}^{B} r\right) I_{1}\left(k_{j}^{B} r\right) s_{2}}{k_{i}^{B} k_{j}^{B} I_{0}\left(k_{i}^{B} r_{1}\right) I_{0}\left(k_{j}^{B} r_{1}\right)}\right] \text {, }
\end{aligned}
$$

where $s_{1}=1=\cos (0)$ for this case where $z=0$. Also, in this case, $s_{2}=1=$ $\cos (0) \cdot \cos (0)$.

To find the total value $\left(P_{\mathrm{CB}}\right)$, Eq. (48) is integrated from $r=0$ to $r=r_{1}$. To keep the algebra to manageable proportions, this integral is broken out into three parts, as shown in Eq. (50),

$$
P_{C B}=\int_{0}^{L_{1}} \pi R_{S C}\left|H_{\phi}^{D}\right|^{2} r d r=\pi R_{S C}\left(Q_{4}+Q_{5}+Q_{6}\right)^{.} .
$$

Here, $Q_{4}, Q_{5}$, and $Q_{6}$ represent the definite integrals of $r$ times the first, second, and third terms, respectively, of Eq. (49); therefore,

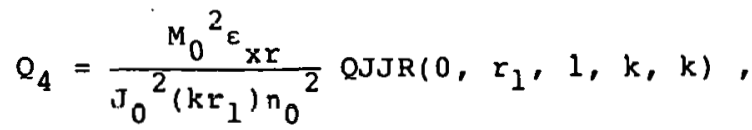

$$
\begin{aligned}
& Q_{5}=\frac{2 M_{0}{ }^{2} \varepsilon_{x r} k}{J_{0}\left(k r_{1}\right) n_{0}{ }^{2}} \sum_{m=1}^{\infty}\left(\frac{M_{m}}{M_{0}}\right) \frac{\operatorname{QIJR}\left(0, r_{1}, i, k_{m}{ }^{B}, k\right) s_{1}}{k_{m}^{B} I_{0}\left(k_{m}^{B} r_{1}\right)}, \\
& Q_{6}=\frac{M_{0}{ }^{2} \varepsilon_{x r} k^{2}}{n_{0}{ }^{2}} \sum_{i=1}^{\infty} \sum_{j=1}^{\infty}\left(\frac{M_{i}}{M_{0}}\right)\left(\frac{M_{j}}{M_{0}}\right) \frac{\operatorname{QIIR}\left(0, r_{1}, 1, \kappa_{i}{ }^{B}, k_{j}{ }^{B}\right) s_{2}}{k_{i}{ }^{B} k_{j}{ }_{j} I_{0}\left(k_{i}{ }^{B} r_{l}\right) I_{0}\left(\kappa_{j}^{B} r_{1}\right)} .
\end{aligned}
$$


$P_{C B}$ is therefore given by Eqs. $(50),(51),(52)$, and (53).

Computation of $P_{C A}$-- The computation of $P_{C A}$ is quite similar to that of $P_{C B}$ so that Eq. (54) follows immediately.

$$
\mathrm{dP}_{\mathrm{CA}}=\pi \mathrm{R}_{\mathrm{SC}}\left|\mathrm{H}_{\phi}{ }^{\mathrm{A}}\right|^{2} \mathrm{rdr}
$$

From Eq. (19),

$$
\begin{aligned}
& \left|\mathrm{H}_{\phi}^{A}\right|^{2}=\frac{1}{n_{0}^{2}}\left\{\left[\frac{\mathrm{aM}_{0} \mathrm{G}_{1}\left(\mathrm{k}_{0} \mathrm{r}\right)}{\mathrm{G}_{0}\left(\mathrm{k}_{0} \mathrm{r}_{1}\right)}\right]^{2}+\right. \\
& +2 \sum_{n=1}^{\infty} a_{0} \frac{G_{1}\left(k_{0} r\right)}{G_{0}\left(k_{0} r_{1}\right)} c_{n} \frac{k_{0}}{k_{n}^{A}} \frac{D_{1 n}\left(k_{n}^{A} r\right)}{D_{0 n}\left(k_{n}^{A} r_{1}\right)} s_{1}+ \\
& \left.+\sum_{i=1}^{\infty} \sum_{j=1}^{\infty} c_{i} \frac{k_{0}}{k_{i}{ }^{A}} \frac{D_{1 i}\left(k_{i}{ }^{A} r\right)}{D_{0 i}\left(k_{i}{ }^{A} r_{1}\right)} c_{j} \frac{k_{0}}{k_{j}{ }^{A}} \frac{D_{1 j}\left(k_{j}{ }^{A} r\right)}{D_{0 j}\left(k_{j}{ }^{A} r_{1}\right)} s_{2}\right\} .
\end{aligned}
$$

Once again, from Eq. (54), let

$$
P_{C A}=\int_{r_{1}^{2}}^{r_{2}} \pi R_{s c}\left|H_{\phi}^{A}\right|^{2} r d x=\pi R_{s c}\left(Q_{1}+Q_{2}+Q_{3}\right),
$$

where, as before, $Q_{1}, Q_{2}, Q_{3}$ represent the definite integrals of $r$ times the first, second, and third terms, respectively, on the right side of Eq. (55). Now, by using Eqs. (55), (56), and (10), the value of $Q_{1}$ is found to be

$$
\begin{aligned}
Q_{1} & =\frac{a^{2}}{n_{0}^{2}} \frac{M_{0}^{2}}{G_{0}^{2}\left(k_{0} r_{1}\right)}\left[\mathrm{N}_{0}{ }^{2}\left(k_{0} r_{2}\right) \operatorname{QJJR}\left(r_{1}, r_{2}, 1, k_{0}, k_{0}\right)-\right. \\
& -2 N_{0}\left(k_{0} r_{2}\right) J_{0}\left(k_{0} r_{2}\right) \operatorname{QJNR}\left(r_{1}, r_{2}, 1, k_{0}, k_{0}\right)+ \\
& \left.+J_{0}^{2}\left(k_{0} r_{2}\right) \operatorname{QNNR}\left(r_{1}, r_{2}, 1, k_{0}, k_{0}\right)\right] .
\end{aligned}
$$

Taking the product of Eqs. (10) and (14) shows that

$$
\begin{aligned}
& G_{1}\left(k_{0} r\right) D_{1 n}\left(k_{n}^{A} r\right)=\left[J_{1}\left(k_{0} r\right) N_{0}\left(k_{0} r_{2}\right)-\right. \\
& \left.-J_{0}\left(k_{0} r_{2}\right) N_{1}\left(k_{0} r\right)\right] I_{1}\left(k_{n}^{A} r\right) k_{0}\left(k_{n}^{A} r_{2}\right)+ \\
& +\left[J_{1}\left(k_{0} r\right) N_{0}\left(k_{0} r_{2}\right)-J_{0}\left(k_{0} r_{2}\right) N_{1}\left(k_{0} r\right)\right] I_{0}\left(k_{n}^{A} r_{2}\right) k_{1}\left(k_{n}^{A} r\right)
\end{aligned}
$$

Therefore, substituting Eq. (58) into Eq. (55) and using Eq. (56) gives 


$$
\begin{aligned}
Q_{2} & =\frac{2}{n_{0}{ }^{2}} \frac{a_{0} k_{0}}{G_{0}\left(k_{0} r_{1}\right)} \sum_{n=1}^{\infty}\left\{\frac{c_{n} s_{1}}{k_{n}^{A} D_{0 n}\left(k_{n}^{A} r_{1}\right)}\right. \\
& -\left[N_{0}\left(k_{0} r_{2}\right) k_{0}\left(k_{n}^{A} r_{2}\right) \operatorname{QIJR}\left(r_{1}, r_{2}, 1, k_{n}{ }^{A}, k_{0}\right)-\right. \\
& -J_{0}\left(k_{0} r_{2}\right) K_{0}\left(k_{n}^{A} r_{2}\right) \operatorname{QINR}\left(r_{1}, r_{2}, 1, k_{n}^{A}, k_{0}\right)+ \\
& +N_{0}\left(k_{0} r_{2}\right) I_{0}\left(k_{n}^{A} r_{2}\right) \operatorname{QKJR}\left(r_{1}, r_{2}, 1, k_{n}^{A}, k_{0}\right)- \\
& \left.\left.-J_{0}\left(k_{0} r_{2}\right) I_{0}\left(k_{n}^{A} r_{2}\right) \operatorname{QKNR}\left(r_{1}, r_{2}, 1, k_{n}{ }^{A}, k_{0}\right)\right]\right\}
\end{aligned}
$$

From Eq. (14), it is found that

$$
\begin{aligned}
& D_{1 i}\left(k_{i}^{A} r\right) D_{1 j}\left(k_{j}^{A} r\right)= \\
& {\left[\ddot{I}_{1}\left(k_{i}^{A} r\right) K_{n}\left(k_{i}^{A} r_{2}\right)+I_{n}\left(k_{i}^{A} r_{2}\right) K_{1}\left(k_{i}^{A} r\right)\right] I_{1}\left(k_{j}^{A} r\right) K_{n}\left(k_{j}^{A} r_{2}\right)+} \\
& +\left[I_{1}\left(k_{i}^{A} r\right) K_{0}\left(k_{i}^{A} r_{2}\right)+I_{0}\left(k_{i}^{A} r_{2}\right) K_{1}\left(k_{i}^{A} r\right)\right] I_{0}\left(k_{j}^{A} r_{2}\right) K_{1}\left(k_{j}^{A} r\right) .
\end{aligned}
$$

Substituting Eq. (60) into Eq. (55) yields

$$
\begin{aligned}
& Q_{3}=\frac{k_{0}^{2}}{n_{0}^{2}} \sum_{i=1}^{\infty} \sum_{j=1}^{\infty}\left\{\frac{c_{i} s_{2} c_{j}}{k_{i}^{A} k_{j}^{A} D_{0 i}\left(k_{i}^{A} r_{1}\right) D_{0 j}\left(k_{j}^{A} r_{1}\right)} .\right. \\
& \text { - }\left[k_{0}\left(k_{i}^{A} r_{2}\right) k_{0}\left(\kappa_{j}^{A} r_{2}\right) \operatorname{QIIR}\left(r_{1}, r_{2}, 1, k_{i}{ }^{A}, k_{j}{ }^{A}\right)+\right. \\
& +I_{0}\left(\kappa_{i}^{A} r_{2}\right) K_{0}\left(\kappa_{j}^{A} r_{2}\right) \operatorname{QKIR}\left(r_{1}, r_{2}, 1, \kappa_{i}{ }^{A}, \kappa_{j}{ }^{A}\right)+ \\
& +k_{0}\left(k_{i}^{A} r_{2}\right) \bar{I}_{0}\left(\kappa_{i}^{\lambda} r_{2}\right) \operatorname{QRIR}\left(r_{1}, r_{2}, 1, k_{i}{ }^{n}, \kappa_{i}{ }^{A}\right)+ \\
& \left.\left.+I_{0}\left(k_{1}^{A} r_{2}\right) I_{0}\left(k_{j}{ }^{A} r_{2}\right) \operatorname{OKKKR}\left(r_{1}, r_{2}, 1, k_{i}{ }^{A}, k_{j}{ }^{A}\right)\right]\right\} \text {. }
\end{aligned}
$$

Then $P_{C A}$ is calculated from Eqs. $(56),(57),(59)$, and $(61)$.

Computation of $\mathrm{P}_{\mathrm{OC}}$-- Since the only $\mathrm{H}$ fields in the resonator are those directed in the $\phi$ direction, the only currents which can flow in the resonator walls at $r=r_{1}$ and $r=r_{2}$ are those in the $z$ direction (Figure 4 ).

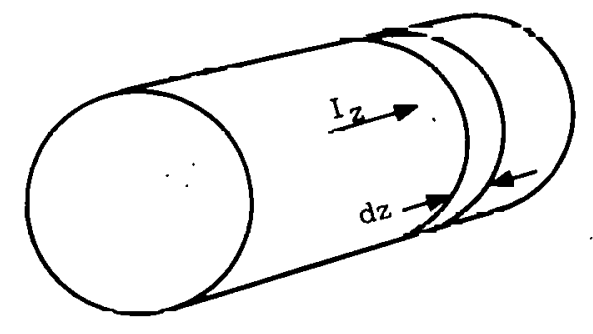

Figure 4. 2-Directed Current Flowing across an Incremental Band on a Cylindrical Surface 
With reference to Figure 4 , it is evident that the incremental power (dP oc) dissipated in the incremental band of length $\mathrm{dz}$ will be given by

$$
\mathrm{dP}_{\mathrm{OC}}=\frac{\left|\mathrm{I}_{\mathrm{rms}}\right|^{2} \mathrm{R}_{\mathrm{SOC}} \mathrm{dz}}{2 \pi \mathrm{r}_{2}}
$$

$\dot{I}_{\text {rms }}$ is the total rms current flowing across the incremental band, and $R_{\text {soc }}$ is. the surface resistivity of the outer conductor at $r=r_{2} \cdot R_{\text {soc }}$ is given by

$$
R_{\text {SOC }}=\sqrt{\pi f \mu_{2} P_{2}}
$$

Values $\mu_{2}$ and $\rho_{2}$ are the permeability and bulk resistivity, respectively, of the outer conductor metal.

Since

$$
\left|\mathrm{I}_{\mathrm{rms}}\right|=\frac{2 \pi \mathrm{r}_{2}\left|\mathrm{H}_{\phi}^{\mathrm{A}}\right| \mathrm{r}_{2}}{\sqrt{2}}
$$

Eq. (62) may be rewritten as

$$
\mathrm{dP}_{\mathrm{OC}}=\pi\left|\mathrm{H}_{\phi}^{\mathrm{A}}\right|_{\mathbf{r}_{2}}^{2} \mathbf{r}_{2} \mathrm{R}_{\text {Soc }} \mathrm{dz}
$$

so that the total power $\left(P_{o c}\right)$ is given by

$$
P_{\text {OC }}=\pi r_{2} R_{\text {SOC }} \int_{0}^{L}\left|H_{\phi}^{A}\right|_{r_{2}}^{2} d z
$$

By using Eq. (19), and the orthogonality relations, one gets

$$
P_{\text {OC }}=\frac{\pi r_{2}{ }^{R} \operatorname{soc}^{L}}{n_{0}^{2}}\left\{\left[\frac{a_{0} G_{1}\left(k_{0} r_{2}\right)}{G_{0}\left(k_{0} r_{1}\right)}\right]^{2}+\frac{1}{2} \sum_{n=1}^{\infty}\left[\frac{C_{n} k_{0} D_{1 n}\left(k_{n}^{A} r_{2}\right)}{{ }^{{ }^{A}}{ }_{n}^{A} D_{0 n}\left(k_{n}{ }^{A} r_{1}\right)}\right]^{2}\right\} .
$$

Computation of $\mathrm{P}_{b}$-- The computation of $\mathrm{P}_{b^{\prime}}$, the power dissipated in the base plate of the resonator at $z=L$, is very similar to that for $P_{C A}$ as described earlier. In fact,

$$
P_{b}=\pi R_{s b}\left(Q_{1}+Q_{2}^{\prime}+Q_{3}^{\prime}\right)
$$

where $R_{g b}$ is the surface resistivity of the base plate and is given by

$$
R_{s b}=\sqrt{\pi f H_{3} n_{3}}
$$

Values $\mu_{3}$ and $\rho_{3}$ are the permeability and bulk resistivity, respectively, of the base plate. $Q_{2}^{\prime}$ is the same as $Q_{2}^{\prime}$ in Eq. (59), provided that 


$$
s_{1}=\cos (m)=(-1)^{n}
$$

Similarly, $Q_{3}$ is the same as $Q_{3}$ in $\mathrm{Eq}$. (61) with the provision that

$$
s_{2}=\cos (\pi i) \cos (\pi j)=(-1)^{i+j} \text {. }
$$

Thus, $P_{b}$ is computed using Eqs. $(68),(69),(57),(59),(70),(61)$, and (71).

$$
\text { Computation of } P_{i c}-- \text { The computation of } P_{i c} \text {, the power dissipated on the }
$$

periphery of the inner conductor, is somewhat similar to that for $P_{\text {oc }}$ so that, from Eq. $(66)$,

$$
P_{i c}=\pi r_{1} R_{\text {sic }} \int_{d}^{L}\left|H_{\phi}^{A}\right|_{r_{1}}^{2} d z
$$

can be derived. Here, $R_{\text {sic }} 1$ s the surtace resistivity of the inner conductor and is given by

$$
R_{\text {sic }}=\sqrt{\pi f \mu_{4} \rho_{4}} \text {. }
$$

Values $\mu_{4}$ and $\rho_{4}$ are the permeability and bulk rcsistivity of the inner conductor. Using Eq. (19) to express the value of $\left|\mathrm{H}_{\phi}{ }^{\mathrm{A}}\right|_{r_{1}}^{2}$ and looking forward a little, it becomes apparent that the values of two definite trigonometric integrals will be required. These will now be evaluated in advance.

$$
\int_{d}^{L} \cos \left(\frac{n^{\pi} E}{L}\right) d z=\frac{L}{n^{\pi}}\left[\sin \left(\frac{n^{\pi} z}{L}\right)\right]_{z=d}^{z=L}
$$

so

$$
\int_{d}^{L} \cos \left(\frac{n \pi z}{L}\right) d z=-\frac{L}{n \pi} \sin \left(\frac{n \pi d}{L}\right)
$$

The second integral is

$$
\begin{aligned}
& \int_{d}^{L} \cos \left(\frac{\pi i z}{L}\right) \cos \left(\frac{\pi j z}{L}\right) d z \\
& =\frac{L}{\lambda_{i} \pi(i+j)} \int_{d}^{L}\left[\cos \frac{\pi}{L}(i+j) z\right]\left[\frac{\pi(i+j) d z}{L}\right]+ \\
& +\frac{L}{2 \pi(i-j)} \int_{d}^{L}\left[\cos \frac{\pi}{L}(i-j) z\right]\left[\frac{\pi}{L}(i-j) d z\right] .
\end{aligned}
$$


Therefore, if $i \neq j$

$$
\int_{d}^{L} \cos \left(\frac{\pi i z}{L}\right) \cos \left(\frac{\pi j z}{L}\right) d z=\frac{L}{2 \pi}\left[\frac{\sin \frac{\pi}{L}(i-j) d}{j-i}-\frac{\sin \frac{\pi}{L}(i+j) d}{j+i}\right] \text {. }
$$

If, however, $i=j$, then

$$
\begin{aligned}
\int_{d}^{L} \cos \left(\frac{\pi i z}{L}\right) \cos \left(\frac{\pi j z}{L}\right) d z & =\frac{L}{\pi i} \int_{d}^{L}\left[\cos ^{2}\left(\frac{\pi i z}{L}\right)\right]\left[\frac{\pi i d z}{L}\right] \\
& =\frac{L}{\pi i} \int_{\frac{\pi i d}{L}}^{\frac{\pi}{L}} \cos ^{2}(u) d u \\
& =\frac{L}{\pi i}\left[\frac{u}{2}+\frac{\sin (2 u)}{4}\right]_{\frac{\pi i d}{L}}^{\pi i} .
\end{aligned}
$$

So, if $i=j$, then

$$
\int_{d}^{L} \cos \left(\frac{\pi i z}{L}\right) \cos \left(\frac{\pi j z}{L}\right) d z=\frac{L}{\pi} i\left[\frac{\pi i}{2}-\frac{\pi i d}{2 L}-\frac{1}{4} \sin \left(\frac{2 \pi i d}{L}\right)\right] .
$$

Now, define

$$
H_{i j} \equiv\left\{\begin{array}{l}
\frac{L}{2 \pi}\left[\frac{\sin \frac{\pi}{L}(i-j) d}{j-i}-\frac{\sin \frac{\pi}{L}(i+j) d}{j+i}\right] \text { if } i \neq j \neq j \\
\frac{L}{\pi i}\left[\frac{\pi i}{2}\left(1-\frac{d}{L}\right)-\frac{1}{4} \sin \frac{2 \pi i d}{L}\right] \text { if } i=j
\end{array}\right\}
$$

From Eqs. (72), (19), (75), and $(80)$,

$$
\begin{aligned}
& P_{i c}=\frac{\pi r_{1} R_{s i c}}{n_{0}^{2}}\left\{\left[\frac{a M_{0} G_{1}\left(k_{0} r_{1}\right)}{G_{0}\left(k_{0} r_{1}\right)}\right]^{2}(L-d)-\right. \\
& -2 L k_{0} \frac{a M_{0} G_{1}\left(k_{0} r_{1}\right)}{\pi G_{0}\left(k_{0} r_{1}\right)} \sum_{n=1}^{\infty} \frac{c_{n} D_{1 n}\left(k_{n}{ }^{A} r_{1}\right)}{k_{n}{ }^{A} D_{0 n}\left(k_{n}{ }^{A} r_{1}\right)} \sin \left(\frac{\pi n d}{L}\right)\left(\frac{1}{n}\right)+
\end{aligned}
$$

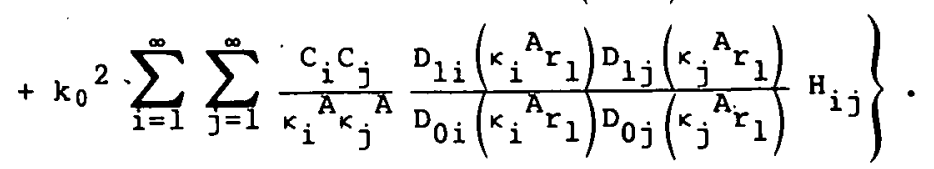


Computation of $\mathrm{P}_{e}$-- The computation of $\mathrm{P}_{e}$, the power dissipated on the end of the center conductor, is essentially the same as that described for $P_{C B}$ Therefore,

$$
P_{e}=\pi R_{s i c}\left(Q_{4}+Q_{5}^{\prime}+Q_{6}^{\prime}\right)
$$

$R_{\text {sic }}$ and $Q_{4}$ are given by Eqs. (73) and (51), respectively. $Q_{5}{ }^{\prime}$ is given by Eq. (52), provided that

$$
s_{1}=\cos (m \pi)=(-1)^{m}
$$

and $Q_{6}$ is the same as $Q_{6}$ in $\mathrm{Eq} .(53)$, provided that

$$
s_{2}=\cos (\pi i) \cos (\pi j)=(-1)^{i+j} .
$$

All wall losses have now been computed.

compuzazion or $\mathrm{r}_{\mathrm{r}}$

The resonator is exclted by driving a small loop (of area F) which is located in the base (at $z=L$ ) at a radius of $r_{L}=\left(r_{1}+r_{2}\right) / 2$. The plane of the loop is in the radial direction. The response of the resonator is sensed by a second identical loop which is diametrically opposite to the first one. Both the exciting source and the sensing receiver present a 50-ohm impedance to their respective loops. The rms voltage ( $\left.\mathrm{v}_{\mathrm{rms}}\right)$ induced in each loop is given by

$$
v_{\text {rms }}=\omega \mu_{0} \frac{\left|H_{L}\right|}{\sqrt{2}} F
$$

Here, $\mathrm{H}_{\mathrm{T}}$ is the magnetic field at the loop and normal to it. Therefore, the power $P_{e x}$, coupled from each loop to the external 50 -ohm load is given by

$$
P_{e x}=\frac{\omega^{3} \mu_{0}^{3}\left|\check{H}_{L}\right|^{3} \bar{F}^{3}}{(2)(50)} \text {. }
$$

Since there are two identical loops, the total power $\left(P_{C}\right)$ coupled out of the resonator is

$$
P_{C}=2 P_{e x}=\frac{2 \omega^{2} \mu_{0}^{2}\left|H_{L}\right|^{2} F^{2}}{(2)(50)} .
$$

Using Eq. (19), $\left|\mathrm{H}_{\mathrm{L}}\right|^{2}$ is found to be

$$
\begin{aligned}
\left|H_{L}\right|^{2} & =\left|H_{\phi}{ }^{A}\right|_{r_{L}}^{2}=\frac{1}{n_{0}^{2}}\left\{\left[a M_{0} \frac{G_{1}\left(k_{0} r_{L}\right)}{\left(k_{0} r_{1}\right)}\right]^{2}+\right. \\
& +2 a M_{0} k_{0} \frac{G_{1}\left(k_{0} r_{L}\right)}{G_{0}\left(k_{0}{ }^{r} 1\right.} \sum_{n=1}^{\infty} \frac{c_{n}}{k_{n}{ }^{A}} \frac{D_{1 n}\left(k_{n}{ }^{A} r_{L}\right)}{D_{O n}\left(k_{n}{ }^{A} r_{1}\right)} s_{1}+
\end{aligned}
$$




$$
\left.+k_{0}{ }^{2} \sum_{i=1}^{\infty} \sum_{j=1}^{\infty} \frac{c_{i} D_{1 i}\left(k_{i}{ }^{A} r_{L}\right)}{k_{i}{ }^{A} D_{0 i}\left(k_{i}{ }^{A} r_{1}\right)} \frac{c_{j}{ }^{D_{1 j}}\left(k_{j}{ }^{A} r_{L}\right)}{k_{j}{ }^{{ }^{A} D_{0 j}}\left(k_{j}{ }^{{ }^{A} r_{1}}\right)} s_{2}\right\} .
$$

where $S_{1}$ and $S_{2}$ are given by Eqs. $(70)$ and $(71)$, respectively. ${ }^{P_{C}}$ is computed directly from Eq. (87) in place of the technique proposed by Karpova. Discussion of this last sentence and the means for determining the value of $F^{2}$ appear at the end of the sertion which follows.

Computation of $\mathrm{P}_{\mathrm{J}}$

As described earlier, the resonator was constructed so that the center conductor can slide in the base block to accommodate unknown samples of various lengths. The resistance in the joint $\left(R_{J}\right)$ is of the order of $1 \mathrm{~m} \Omega$ which becomes significant when measuring samples with very small loss tangents. Since all interior surfaces of the cavity are either copper- or silver-plated, the power dissipated in the joint $\left(P_{J}\right)$ must be accounted for.

If $I_{r m s}$ is the rms current flowing across the joint, then

$$
P_{J}=\left|I_{r m s}\right|^{2} R_{J},
$$

where

$$
I_{r m s}=2 \pi r_{1}\left|\frac{H_{\phi}^{A}}{\sqrt{2}}\right|_{r_{1}, L},
$$

so; using Egs. (19), (89), and (90),

$$
\begin{aligned}
& P_{J}=\frac{2 \pi^{2} r_{1}{ }^{2} R_{J}}{n_{0}{ }^{2}}\left\{\left[a M_{0 G_{0}\left(k_{0} r_{1}\right)}\right]^{2}+\right. \\
& +2 a M_{0} k_{0} \frac{G_{1}\left(k_{0} r_{1}\right)}{G_{0}\left(k_{0} r_{1}\right)} \sum_{n=1}^{\infty} \frac{C_{n}}{k_{n}{ }^{A}} \frac{D_{1 n}\left(k_{n}{ }^{A} r_{1}\right)}{D_{0 n}\left({ }_{n}{ }^{A} r_{1}\right)} s_{1}+ \\
& \left.+k_{0}{ }^{2} \sum_{i=1}^{\infty} \sum_{j=1}^{\infty} \frac{c_{i} D_{1 i}\left(k_{i}{ }^{A} r_{1}\right)}{k_{i}{ }^{A} D_{0 i}\left(k_{i}{ }^{A} r_{1}\right)} \frac{c_{j} D_{1 j}\left(k_{j}{ }^{A} r_{1}\right)}{k_{j}{ }^{A} D_{0 j}\left(k_{j}{ }^{A} r_{1}\right)} s_{2}\right\} \text {. }
\end{aligned}
$$

At this point, expressions for all quantities needed to compute TAND from Eq. (25) are available. It remains only to discuss an accurate means for determining the squared area $\left(F^{2}\right)$ in Eq. (87). Since the loops are small and usually of irregular shape, it is difficult to perform an accurate physical measurement of $\mathrm{F}$. It is, however, easy to determine the effective value of $F^{2}$ empirically. Once $F^{2}$ has been determined, it does not change so long as the coupling loops are not physically changed or moved; hence, after $F^{2}$ is once determined, there is no further need to make empty resonator measurements. (With Karpova's technique, this would be necessary every time the sample length (d) is changed.) 
The determination of the effective value of $F^{2}$ proceeds as follows:

1. The empty cavity resonant frequency $\left(F_{0}\right)$ and $Q_{0}$ are measured for an arbitrary but known (nonzero) value of $d$.

2. An estimate of the joint resistance $\left(R_{J}\right)$ is obtained from dc measurements.

3. Various values of $\mathrm{F}^{2}$ are substituted into $\mathrm{Eq}$. (25) (along with the values of $F_{0}, Q_{0}$, and $R_{J}$ which were obtained in steps 1 and 2 ) until a value for TAND which is as close to 0.0 as desired results.

Thus, the effective value of $F^{2}$ may be first determined as accurately as desired. That value will, of course, be valid for measurements on any subsequent dielectric sample of any length $d$. The effective value of $\mathrm{F}^{2}$ thus derived will be quite consistent with an estimate based on physical measurement.

Finally, it may be noted that the value of $M_{0}$, which appears in numerous equations, is arbitrary, so it can conveniently be assiqned a value of unity. This is true because each of the $W$ and $P$ terms in the expression for TAND, Eq. (25), is proportional to $M_{0}{ }^{2}$; therefore, $M_{0}$ cancels out since TAND involves the $P$ and $W$ terms only in ratios of one to the other. (To verify the asserted proportionality of each of the $P$ and $W$ terms to $M_{0}$, it is necessary to note from Eq. (23). that $C_{n}$ is proportional to $\mathrm{M}_{0} \cdot$ )

Experimental Results

A reentrant cavity of the type suggested by the sketch in Figure 2 has been constructed for use in the VHF region. Three different barrels of different lengths were constructed to permit measurements at three different frequencies. As mentioned earlier there is a snug, sliding fit between the center conductor and the base block, thereby allowing the measurement of samples of different lengths. The compression screw. forces intimate contact between the dielectric sample and the center conductor and cover of the cavity. The results of measurements made on Teflon, polystyrene, nylon, and fused silica are shown in Table 1 . In addition, results from Reference 4 are given to provide a baseline by which the results may be judged. It is apparent that there is still work to be done--particularly in the loss tangent results. It is believed that most of the problems are caused by the variability of the resistance $\left(R_{J}\right)$ between the center conductor and base block of the cavity. Variations of $0.1 \mathrm{~m} \Omega$ produce dramatic shifts when measuring low-loss materials such as fused silica, etc. Work to eliminate this variability is continuing.

A word about the number of terms used to approximate the several infinite series is in order. A careful study of the trade-offs between accuracy and number of terms has not been conducted, so it is quite probable that more terms were used to obtain the results in Table 1 than were necessary. Two different approximations were used. Nine terms were used in all summations over $\mathrm{m}$. Nine terms were also 
used in all summations over $n$ with one exception: In solving the resonance equation, Eq. (1), more than nine terms were used in the summations over $n$. Each summation over $n$ was terminated at a value $n=n_{1}$ when the following two conditions were met:

1. The magnitude of $\sin \left(\pi a n_{1}\right)$ had to exceed 0.9 .

2. The $n_{1}$ th term of the series had to have a magnitude of less than 0.018 of the $\left(n_{1}-1\right)$ th partial sum.

The value of $n_{1}$ varies with the length of the cavity barrel and the properties of the dielectric sample being measured.

TABLE 1

Results of Dielectric Propcrties Measurements

\begin{tabular}{|c|c|c|c|c|c|}
\hline \multirow[b]{2}{*}{ Material } & \multirow{2}{*}{$\begin{array}{c}\text { Frequency } \\
\qquad(\mathrm{MHz}) \\
\end{array}$} & \multicolumn{2}{|c|}{ Dielectric Constant } & \multicolumn{2}{|c|}{ Loss Tangent } \\
\hline & & Measured & von Hippel & Measured & von Hippel \\
\hline $\begin{array}{l}\text { Teflon } \\
\text { Teflon } \\
\text { Teflon }\end{array}$ & $\begin{array}{l}226 \\
368 \\
490\end{array}$ & $\begin{array}{l}2.08 \\
2.07 \\
2.08\end{array}$ & $\begin{array}{l}2.04 \\
2.04 \\
2.04\end{array}$ & $\begin{array}{l}0.00029 \\
0.00040 \\
0.0013\end{array}$ & $\begin{array}{r}0.00015 \\
.0 .00015 \\
0.00015\end{array}$ \\
\hline $\begin{array}{l}\text { Polystyrene } \\
\text { Polystyrene } \\
\text { Polystyrene }\end{array}$ & $\begin{array}{l}224 \\
361 \\
477\end{array}$ & $\begin{array}{l}2.54 \\
2.54 \\
2.55\end{array}$ & $\begin{array}{l}2.55 \\
2.55 \\
2.55\end{array}$ & $\begin{array}{l}0.00027 \\
0.00032 \\
0.00041\end{array}$ & $\begin{array}{l}0.0002 \\
0.0002 \\
0.0002\end{array}$ \\
\hline $\begin{array}{l}\text { Nylon } \\
\text { NyIon } \\
\text { Nylon }\end{array}$ & $\begin{array}{l}220 \\
353 \\
463\end{array}$ & $\begin{array}{l}3.09 \\
3.08 \\
3.09\end{array}$ & $\begin{array}{l}3.10 \\
3.10 \\
3.10\end{array}$ & $\begin{array}{l}0.016 \\
0.014 \\
0.014\end{array}$ & $\begin{array}{l}0.015 \\
0.015 \\
0.015\end{array}$ \\
\hline $\begin{array}{l}\text { Fused silica } \\
\text { Fused silica } \\
\text { Fused silica }\end{array}$ & $\begin{array}{l}216 \\
342 \\
445\end{array}$ & $\begin{array}{l}3.75 \\
3.80 \\
3.80\end{array}$ & $\begin{array}{l}3.78 \\
3.78 \\
3.78\end{array}$ & $\begin{array}{l}0.00008 \\
0.00033 \\
0.000032\end{array}$ & $\begin{array}{l}0.00004 \\
0.00004 \\
0.00004\end{array}$ \\
\hline
\end{tabular}

References

lo. V. Karpova, "On an Absolute Method of Measurement of Dielectric Properties of a Solid Using a $\pi$-shaped Resonator," Soviet Physics (Solid State), vol 1 , February 1959, pp 220-228.

${ }^{2}$ B. W. Hakki and P. D. Coleman, "A Dielectric Resonator Method of Measuring Inductive Capacities in the Millimeter Range," IRE Transactions on Microwave Theory and Techniques, vol' MTT-8, July 1960, pp 476-485.

${ }^{3}$ s. Ramo, J. R. Whinnery, and T. Van Duzer, Fields and Waves in Communication Electronics (New York: John Wiley and Sons, 1965).

${ }^{4}$ A. von Hippel (ed), Dielectric Materials and Applications, (New York: John Wiley and Sons, 1954), pp 332, 335, 323, 311.

${ }^{5}$. W. McLachlan, Bessel Functions for Engineers (2nd ed, London: oxford at the clarendon Press). 
APPENDIX A

Tabulation of Closed-Form Expressions

This appendix tabulates closed-form expressions for the definite integrals involving Bessel functions which appear in this report. Most of the expressions were obtained from Reference 5; however, Eqs. (A-9) and $(A-10)$ were derived as discussed in Appendix B.

Expressions are given for definite integrals of the form

$$
\int_{Y}^{Z} Y_{v}(k r) Z_{v}(l r) r d r
$$

where $v=0,1,2,3, \ldots$ and $Y$ and $Z$ represent any. of the Bessel functions $J, N, I$, or $\mathrm{K} ; \mathrm{k}$ and $\&$ represent real, positive constants. Two expressions are given for each integral; the first is in terms of Bessel functions of order $v$ and $v+1$; the second is in terms of Bessel functions of order $v$ and $v-1$. Each integral is given in two notations: The first is the standard notation of expression (A-1), the second is the functional notation used in the body of this report, e.g.,

$$
\int_{y}^{z} I_{1}(k r) J_{1}^{;}(l x) r d r=\operatorname{QIJR}(y, z, 1, k, l) .
$$

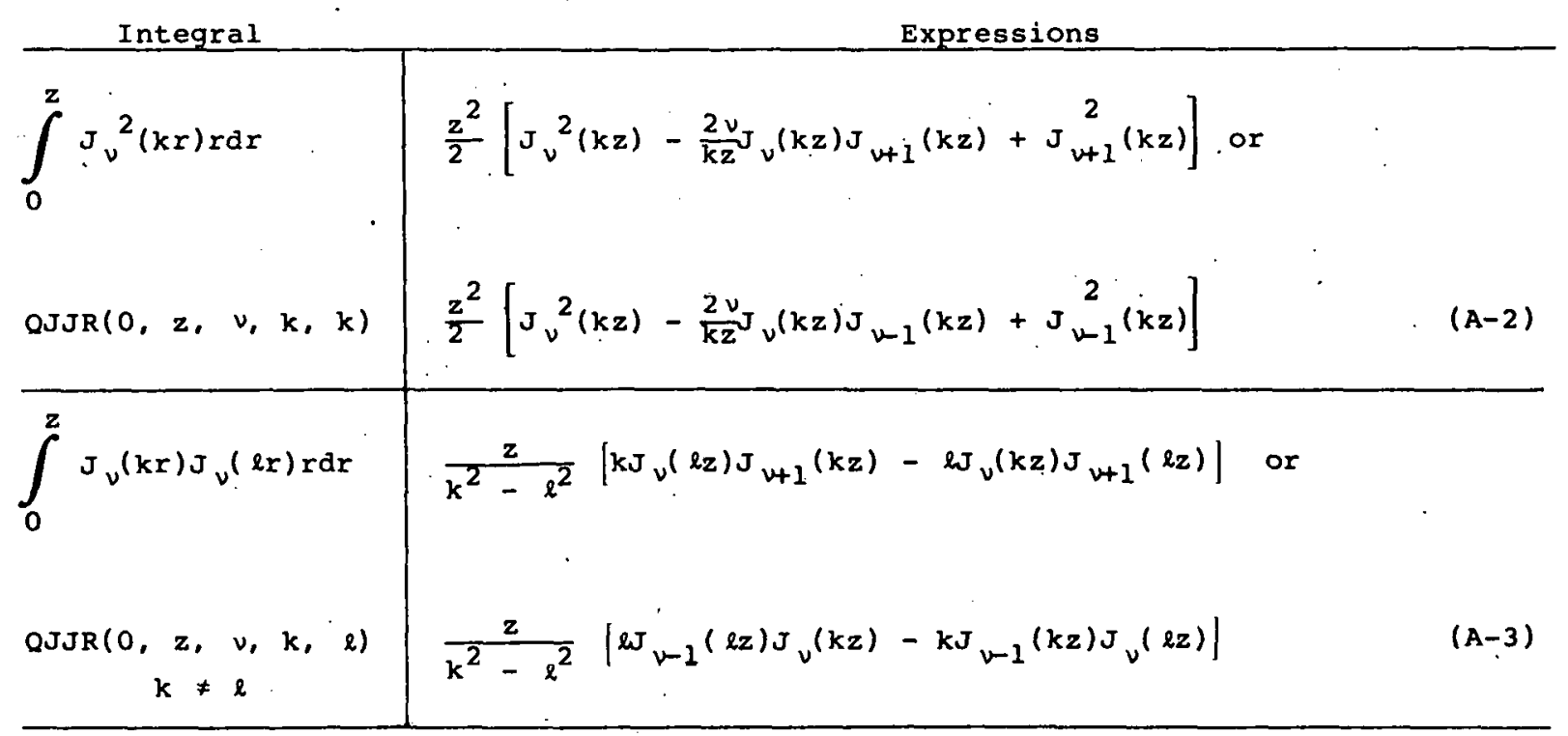




\begin{tabular}{|c|c|c|}
\hline $\mathrm{J}_{\nu}(\mathrm{kr}) \mathrm{N}_{\nu}(\mathrm{kr}) \mathrm{rdr}$ & $\begin{array}{l}\frac{z^{2}}{2}\left\{N_{v}(k z) J_{v}(k z)-\frac{v}{k z}\left\{J_{v+1}(k z) N_{v}(k z)+J_{v}(k z) N_{v+1}(k z)\right\}\right. \\
\left.\quad+N_{v+1}(k z) J_{v+1}(k z)\right] \\
\frac{z^{2}}{2}\left[N_{v}(k z) J_{v}(k z)-\frac{v}{k z}\left\{N_{v-1}(k z) J_{v}(k z)+N_{v}(k z) J_{v-1}(k z)\right\}\right. \\
\left.\quad+N_{v-1}(k z) J_{v-1}(k z)\right]\end{array}$ & $\begin{array}{l}+ \\
\text { or } \\
+\end{array}$ \\
\hline $\begin{array}{l}\int_{0}^{z} J_{v}(k r) N_{v}(\ell r) r d r \\
\left.\text { UJNR(0, } z_{i} v, k, \ell\right) \\
r \neq \varepsilon\end{array}$ & $\begin{array}{l}\frac{z}{k^{2}-\ell^{2}}\left[k N_{v}(\ell z) J_{v+1 .}(k z)-\ell J_{v}(k z) N_{v+1}(\ell z)\right] \text { or } \\
\frac{z}{k^{2}-\ell^{2}}\left[\ell N_{v-1}(\ell z) J_{v}(k z)-k J_{v-1}(k z) N_{v}(\ell z)\right]\end{array}$ & $(A-5)$ \\
\hline $\begin{array}{l}\int_{0}^{z} I_{v}(k r) J_{v}(\ell r) r d r \\
\operatorname{QIJR}(0, z, v, k, \ell)\end{array}$ & $\begin{array}{l}\frac{z}{k^{2}+\ell^{2}}\left[k J_{v}(\ell z) I_{v+1}(k z)+\ell I_{v}(k z) J_{v+1}(\ell z)\right] \text { or } \\
\frac{z}{k^{2}+\ell^{2}}\left[k J_{v}(\ell z) I_{v-1}(k z)-\ell I_{v}(k z) J_{v-1}(l z)\right]\end{array}$ & $(A-6)$ \\
\hline $\int_{y}^{z} k_{v}(k r) J v_{v}(\ell r) r d r$ & 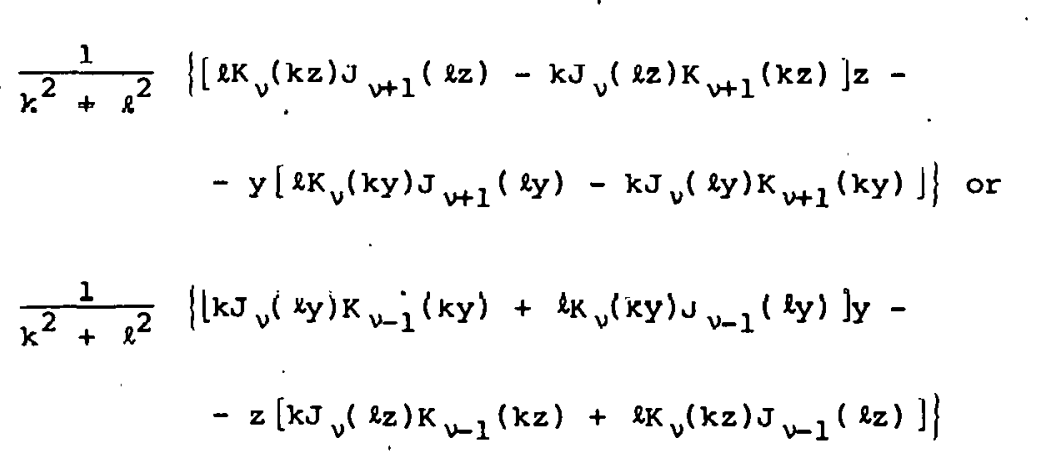 & $(A-7)$ \\
\hline $\int_{0}^{2} N_{1}^{2}(k r) r d r$ & $\begin{array}{l}\frac{z^{2}}{2}\left[N_{v}(k z)-\frac{2 v}{k z} N_{v}(k z) N_{v+1}(k z)+N_{v+1}{ }^{2}(k z)\right] \text { or } \\
\frac{z^{2}}{2}\left[N_{v}{ }^{2}(k z)-\frac{2 v_{N}}{k z} N_{v}(k z) N_{v-1}(k z)+N_{v-1}{ }^{2}(k z)\right]\end{array}$ & $(\Lambda-8)$ \\
\hline $\int_{Y}^{Z} I_{\nu}(k r) N_{v}(\ell r) r d r$ & $\begin{aligned} & \frac{1}{k^{2}+\ell^{2}}\left\{\left[k_{v}(\ell z) I_{v+1}(k z)+\ell I_{v}(k z) N_{v+1}(\ell z)\right] z-\right. \\
&\left.-Y\left[k_{v}(\ell y) I_{v+1}(k y)-\ell I_{v}(k y) N_{v+1}(\ell y)\right]\right\} \text { or }\end{aligned}$ & \\
\hline
\end{tabular}




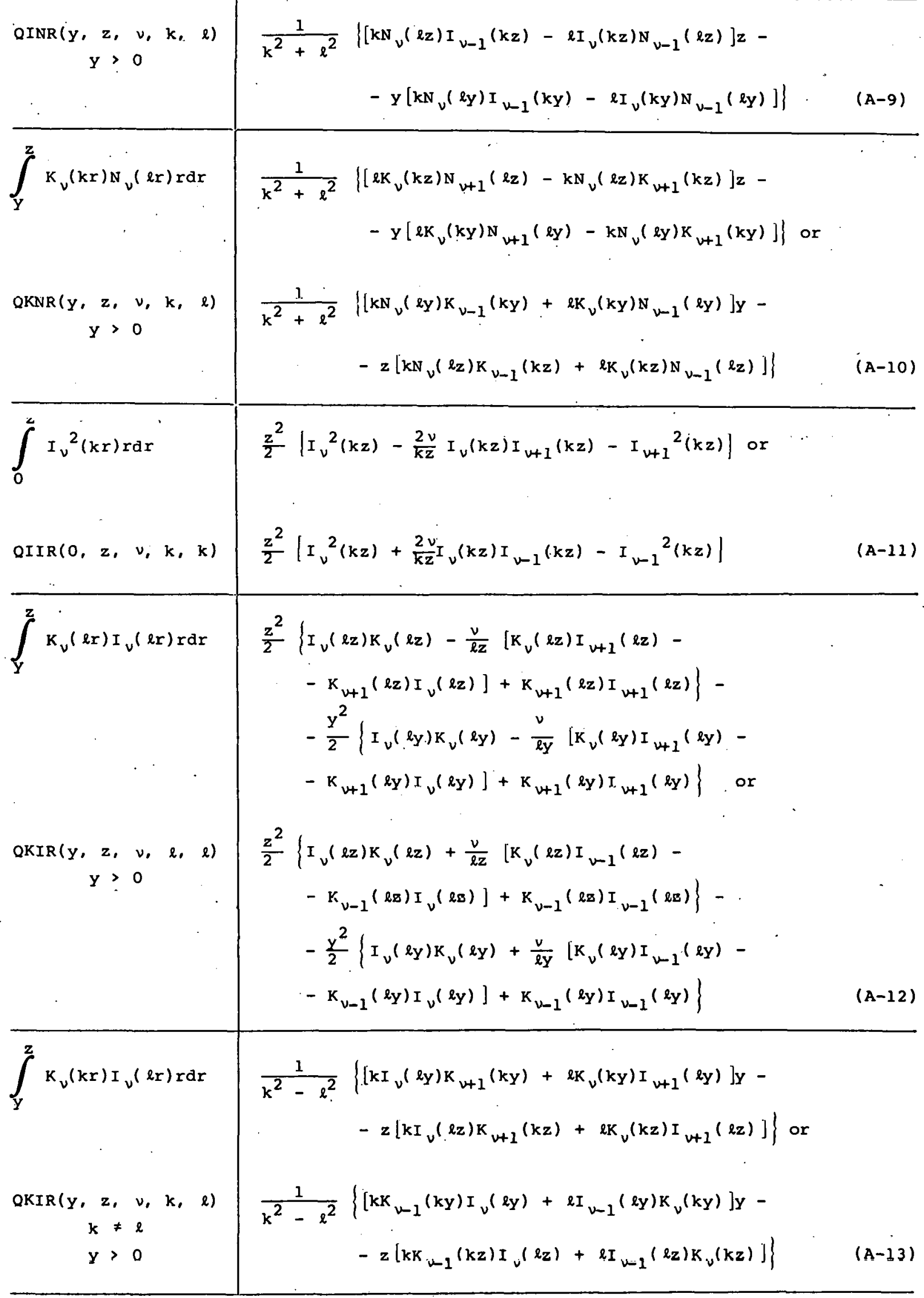




\begin{tabular}{|c|c|c|c|c|}
\hline $\int_{z}^{\infty} k_{v}^{2}(k r) r d r$ & $\frac{z^{2}}{2}$ & {$\left[k_{v+1}^{2}(k z)-\frac{2 v}{k z} k_{v}(k z) k_{v+1}(k z)-k_{v}^{2}(k z)\right]$} & or & \\
\hline $\begin{aligned} \operatorname{QKKR}(z, \infty, & \nu, k, k) \\
z & >0\end{aligned}$ & $\frac{z^{2}}{2}$ & {$\left[k_{\nu-1}{ }^{2}(k z)+\frac{2 v}{k z} k_{\nu}(k z) k_{\nu-1}(k z)-k_{\nu}{ }^{2}(k z)\right]$} & & $(A-14)$ \\
\hline $\int_{z}^{\infty} k_{v}(k r) K_{v}(\ell r) r d r$ & $\overline{\mathrm{k}^{2}}$ & $\frac{z}{-\ell^{2}}\left\{k K_{v}(\ell z) K_{v+1}(k z)-\ell K_{v}(k z) K_{v+1}(\ell z)\right\}$ & or & \\
\hline $\begin{array}{c}\operatorname{QKKR}(z, \infty, v, k, \ell) \\
k \neq \ell \\
z=0\end{array}$ & $\overline{k^{2}}$ & $\frac{z}{-e^{2}}\left\{k K_{v-1}(k z) K_{v}(\ell z)-\ell K_{v-1}(\ell z) K_{v}(k z)\right\}$ & & $(A-15)$ \\
\hline
\end{tabular}


APPENDIX B

Derivation of Equations

This appendix gives the derivation of Eqs: $(A-9)$ and $(A-10)$, which appear in Appendix A. The author is grateful to D. E. Amos of the Numerical Mathematics Division 5642 for outlining this derivation.

From Eq. (2) on page 190 of Reference 5, the differential equation

$$
y_{1} \cdots+\frac{y_{1}^{\prime}}{z}+\left(e^{2}-\frac{v^{2}}{z^{2}}\right) y_{1}=0
$$

has a solution

$$
\mathrm{y}_{1}=\mathrm{aJ} \mathrm{J}_{v}(\ell z)+\mathrm{bN}_{v}(\ell z)
$$

Also, from Eq. (4) on page 190 of Reference 5, the differential equation

$$
\mathrm{y}_{2}{ }^{\prime}+\frac{\mathrm{y}_{2}^{\prime}}{\mathrm{z}}-\left(\mathrm{k}^{2}+\frac{\mathrm{v}^{2}}{\mathrm{z}^{2}}\right) \mathrm{y}_{2}=0
$$

has a solution

$$
Y_{2}=c I_{v}(k z)+d K_{v}(k z)
$$

In these equations, $a, b, c$, and d are arbitrary constants. Multiplication of Eq. $(B-1)$ by $z^{2} y_{2}$ and $E q .(B-3)$ by $z^{2} y_{1}$ yields

$$
\begin{aligned}
& y_{2} y_{1}^{\prime}{ }^{\prime 2}+z y_{1}^{\prime} y_{2}+\left(e^{2} z^{2}-v^{2}\right) y_{2} y_{1}=0 \\
& y_{1} y_{2}{ }^{\prime} z^{2}+z y_{2} y_{1}-\left(k^{2} z^{2}+v^{2}\right) y_{2} y_{1}=0
\end{aligned}
$$

Subtract Eq. (B-5) from Eq. (B-6) to get

$$
z\left(y_{1} y_{2} \cdots-y_{2} y_{1}^{\prime \prime}\right)+\left(y_{2}^{\prime} y_{1}-y_{1}^{\prime} y_{2}\right)=y_{1} y_{2} z\left(x^{2}+\ell^{2}\right) .
$$

Observe that

$$
\frac{d}{d z}\left[z\left(y_{2}^{\prime} y_{1}-y_{1}^{\prime} y_{2}\right)\right]=z\left(y_{1} y_{2}^{\prime}-y_{2} y_{1}^{\prime}\right)+y_{2}^{\prime} y_{1}-y_{1}^{\prime} y_{2} \cdot \quad(B-8)
$$

Substituting Eq. (B-8) into Eq. (B-7) gives 


$$
\frac{d}{d z}\left|z\left(y_{2}^{\prime} y_{1}-y_{1}^{\prime} y_{2}\right)\right|=y_{1} y_{2} z\left(k^{2}+\ell^{2}\right)
$$

or

$$
y_{1} y_{2} z d z=\frac{d\left[z\left(y_{2}^{\prime} y_{1}-y_{1}^{\prime} y_{2}\right)\right]}{k^{2}+l^{2}}
$$

Integrating from $z_{1}$ to $z_{2}$, where $0<z_{1}<z_{2}<\infty$ yields

$$
\int_{z_{1}}^{z_{2}} y_{1} y_{2} z d z=\left[\frac{z}{k^{2}+\ell^{2}}\left(y_{2}^{\prime} y_{1}-y_{1}^{\prime} y_{2}\right)\right]_{z_{1}}^{z_{2}}
$$

(Actually, if $b=a=0$ in Eqs. $(B-2)$ and $(B-4), z_{1}=0$ is permissible; also, if $c=0$, then $z_{2}=\infty$ is permissible.)

Choooing $a=A=n$ in Eqs, $(B-2)$ and $(B-4)$ and substituting the resulting expressions into tơ. $(b-11)$ lesulls in

$$
\begin{aligned}
& \int_{z_{1}}^{z_{2}} I_{v}(k z) N_{v}(l z) z d z=\left[\frac { z } { k ^ { 2 } + \ell ^ { 2 } } \left\{N_{v}(l z) \frac{d}{d z} I_{v}(k z)-\right.\right. \\
& \left.\left.-I_{v}(k z) \frac{d}{d z} N_{v}(l z)\right\}\right]_{z_{1}}^{z_{2}} .
\end{aligned}
$$

similarly, choosing $a=c=0$ in Eqs. $(B-2)$ and $(B-4)$ and substituting the results into Eq: $(R-11)$ yields

$$
\begin{gathered}
\int_{z_{1}}^{z_{2}} K_{v}(k z) N_{v}(l z) z d z=\left[\frac{\frac{\pi}{k^{2}+\ell^{2}}\left\{N_{v}(l z) \frac{d}{d z} K_{v}(l z z)-\right.}{z_{2}}\right. \\
\left.\left.-K_{v}(k \bar{z}) \frac{d}{d z^{N}} N_{v}(l z)\right\}\right]_{z_{1}}^{z_{2}}
\end{gathered}
$$

From Eqs. $3.27(14 a), 3.27(14 b), 3.27(9), 3.27(10), 3.27(15 a)$, and $3.27(15 b)$ of Roference 3 , one obtains

$$
\frac{d}{d z} I_{\nu}(k z)=\frac{v}{z} I_{v}(k z)+k I{ }_{v+1}(k z)
$$

or

$$
\begin{aligned}
& \frac{d}{d z} I_{v}(k z)=-\frac{v}{z} I_{v}(k z)+k I_{v-1}(k z) . \\
& \frac{d}{d z} N_{v}(l z)=\frac{v}{z} N_{v}(l z)-\ell N_{v+1}(l z)
\end{aligned}
$$


or

$$
\begin{aligned}
& \frac{d}{d z} N_{v}(\ell z)=-\frac{v}{z} N_{v}(\ell z)+\ell N_{v-1}(\ell z) . \\
& \frac{d}{d z} K_{v}(k z)=\frac{v}{z} K_{v}(k z)-k K_{v+1}(k z)
\end{aligned}
$$

or

$$
\frac{d}{d z} K_{v}(k z)=-\frac{v}{z} K_{v}(k z)-k K_{v-1}(k z)
$$

Substituting Eqs. $(B-14),(B-15),(B-16)$, and $(B-17)$ into Eq. (B-12) yields Eq. (A-9). Similarly, substituting Eqs. (B-18), (B-19), (B-16), and (B-17) into Eq. (B-13) yields Eq. (A-10). 
DISTRI BUTION :

Erie Technological Products (2)

5 Fraser Ave.

Trenton, Ontario, Canada K8V 551

Attn: J. Johnston

M. Blamire

National Bureau of Standards

Boulder, CO 80303

Attn: H..E. Bussey

$\begin{array}{ll}1252 & \text { W. A. Sebrell } \\ 2152 & \text { J. K. Hartman } \\ 2153 & \text { R. V. Baron } \\ 2153 & \text { I. E. Horner } \\ 2153 & \text { C. P. Stanton } \\ 2343 & \text { P. A. Gelt } \\ 2345 & \text { R. L. O'Nan } \\ 2550 & \text { E. G. Franzak } \\ 2552 & \text { R. A. Erickson } \\ 2552 & \text { R. D. Moyer (15) } \\ 2552 & \text { C. J. Still } \\ 4733 & \text { T.. E. Duda } \\ 4733 & \text { I. K. Warne, Jr. } \\ 4734 & \text { J. E. UhI } \\ 5642 & \text { D. E. Amos } \\ 5642 & \text { L. F. Shampine } \\ 8266 & \text { E. A. Aas } \\ 3141 & \text { T. L. Werner (5) } \\ 3151 & \text { W. L. Garner (3) } \\ \text { DOE/TIC } & \text { For. DOE/TIC (Unlimited Release) }\end{array}$

DOE/TIC (25)

(R. P. Campbel1, 3154-3) 


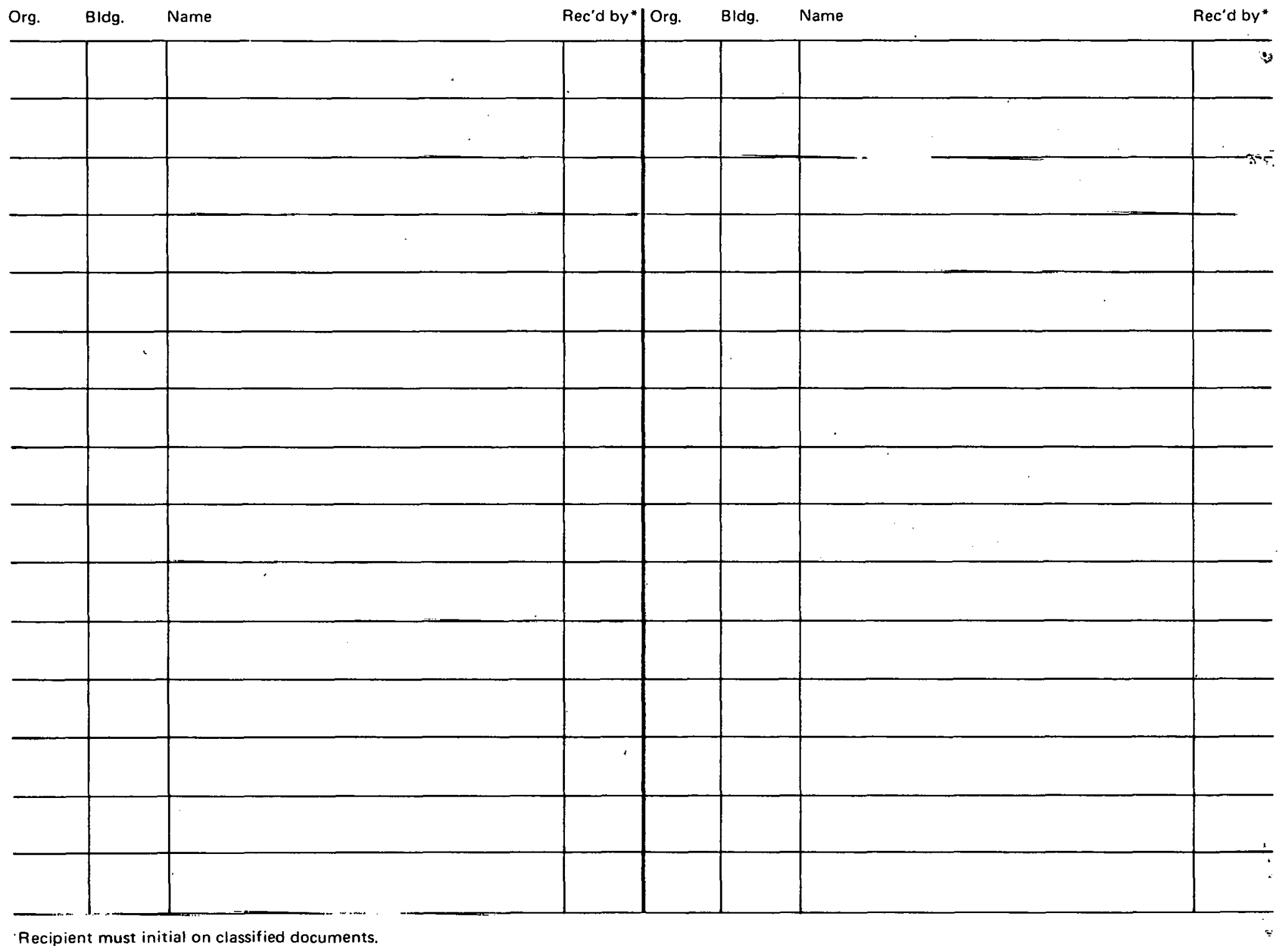

